\title{
Design and Manufacturing of a New Prosthetic Foot
}

\author{
S. K. Mohammed *1 , A. H. Mohammed ${ }^{2}$ \\ ${ }^{1}$ College of Engineering, Uruk University.. Baghdad. Iraq \\ ${ }^{2}$ College of Engineering. University Al- Nahrain.. Baghdad. Iraq
}

salsabil2alanber@gmail.com

\begin{abstract}
All prosthetic foot designs, adapted in common use, don't imitate the specific qualities of a typical human foot. The premise of this task is to explore current prosthetics so as to plan and assemble a more human like prosthesis. In attempted such a structure, the new prosthesis will show a more extensive scope of qualities than those showed in current prosthetic feet. In doing as such, the new prosthesis will give a closer portrayal of the capacities inalienable to an ordinary human foot. The qualities associated with ordinary strolling incorporate dorsiflexion foot test. The qualities showed in the produced new foot tried are contrasted with those of" SACH foot". The qualities showed by prostheses which compared well with those of a human foot were researched further. Another prosthetic foot is structured and made from composite random E-glass-polyester. The premise of the new prosthetic plan consolidates current prosthetic structure components, such as, prosthetic materials and segments. The scientific part presents the aftereffects of the static investigation by techniques, such as, mathematical strategies (Finite Element method FEM) and experimental methods. Thus the new foot was designed and dorsiflexion were measured. The new prosthetic foot has a good characteristic when compared with the SACH foot, such as good dorsiflexion $\left(7^{\circ}-6.4^{\circ}\right)$ respectively.
\end{abstract}

Crossref

$10.36371 /$ port.2020.2.8

Keywords: Prosthetic foot, composite material, dorsiflexion.

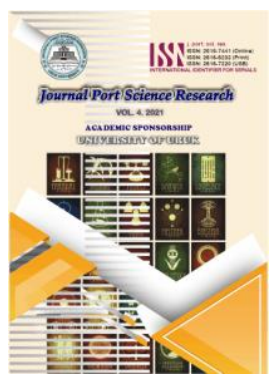

\section{INTRODUCTION}

The human body requires feet so as to give strength and equalization when standing or moving. Removal of a foot fundamentally diminishes the amputees capacity to perform typical exercises, for example, strolling. The fundamental objective of a prosthesis of any kind is to improve or reestablish capacity to a truly disabled person. Current prosthetic feet neglect to precisely mirror the qualities displayed by a typical human foot. Principally the physical constraints of a prosthesis are its powerlessness to reproduce the elements of a sound foot. There are a great number of feet to choose from, some simple and nonadjustable, some more technically sophisticated and adjustable by prosthetist. A foot should meet the lifestyle and prosthetic needs of the patient. One also must consider the maintenance requirements and how they are impacted by the amputees' distance from a prosthetic facility, and the patient's gadget tolerance. On the practical side, the manufacturer must stand behind their foot and offer a reasonable trial period. Today the physician, prosthetist, and physical therapist must be familiar with Medicare guidelines and $\mathrm{K}$ levels. Being informed can help the rehabilitation team to agree upon the componentry best suited for the amputee when generating the prescription. This approach also avoids unnecessary inquiries and helps assure payment. In closing, two statements are added: (1) a wellinformed prosthetist with good communication skills and dedication to the details of socket fit and alignment is for the patient the best source of information concerning componentry; and (2) appropriateness, reliability, and convenience are good, general guidelines to follow when helping an amputee choose a prosthetic foot. [1].There was a assortment of counterfeit foot structures accessible for use with prosthetic feet. The greater part of the plans can be isolated into two classes, articulated feet are feet with moving joints, and non-articulated are feet that do not have moving joints. Generally, articulated feet tend to behavior and require more maintenance than non-articulated feet. Two common articulated feet are the single_axis foot and the multi_axis foot. The single_axis foot has only one joint to allow rotation. Two rubber bumpers are in this foot.

On the other hand, the multi_axis foot, permits some movement around threeaxes. The motion about three axes allows the patient to rotate the foot. This foot allows the patients to walk on uneven terrain. The multi_axis foot is slightly heavier than the singl_axis foot, and need more maintenance [2]. During stair ascent, the Proprio foot resulted in a higher inter limb symmetry than conventional prosthetic feet, with significant differences between the Proprio and SACH/SAFE feet. The swing-phase dorsiflexion appeared to promote greater interlimb symmetry because it facilitated forward motion of the body, resulting in a heeltotoe center of pressure trajectory. During stair descent, all feet had low symmetry without significant differences between feet. The movement strategy used when descending stairs, which is to roll over the edge of a step, had a greater influence on symmetry than the dorsiflexion features of prosthetic feet [3]. 


\section{THE SUGGESTED NEW DESIGN FOOT}

Through the period of work many types of prosthetic feet were studied (specially the feet that designed locally) to optimize the best shape for them and to view the materials and design for it we can list them into the following :

-SACH foot: It is one of the more customary kinds of prosthetic feet which is shown in Figure (1). The keel of this type of foot is made from wood, while the heel is made from rubber. After studying and testing the $\mathrm{SACH}$ foot, it was found that the failure occurs in the toe off and the dorsiflexion angle for it is fair but it depends on the beginning of foot (fingers, part in natural foot). Therefore this part is carried with high amount of bending moment causing failure.

- Niagara foot: it is The foot that acting in tension [4] is low cost with good energy return system as shown in Figure (2).It is noted that this foot contains curve in its design and it was made from polymer. Also the failure takes place at the toe off as in $\mathrm{SACH}$ foot .

- The foot Dr.Kadhim [5]: it is low cost and easily made, from available materials is shown in Figure (3) but it's need casting high cost negative mold from metal and the foot to be made need to heat treatment of the material(polyethylene) and injection machine .

- Muslim's foot [6]: it is shown in figure (4) it's like Dr.Kadhim foot also need to difficult processes to be made .

- Dr.Emad's foot [7]: in this work the foot made from PolyTetraFluoroEthylene with a complex manufacturing process using $\mathrm{CNC}$ machine to reach to the final product and this may be very costly this foot shown in figure (5).
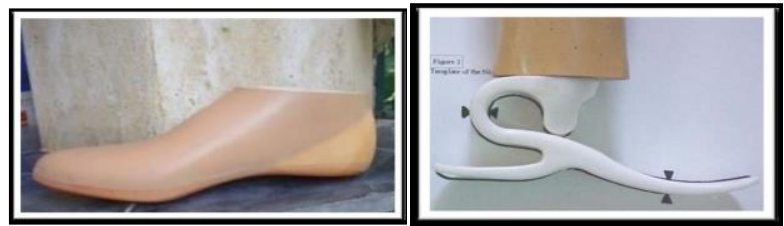

Figure 1. SACH foot

Figure 2. The Niagara foot

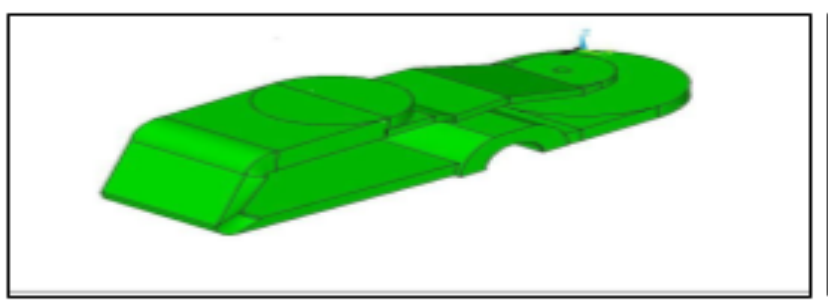

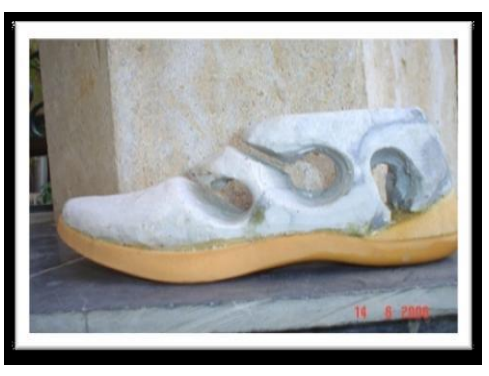

Figure 3. The foot Dr. Kadhim

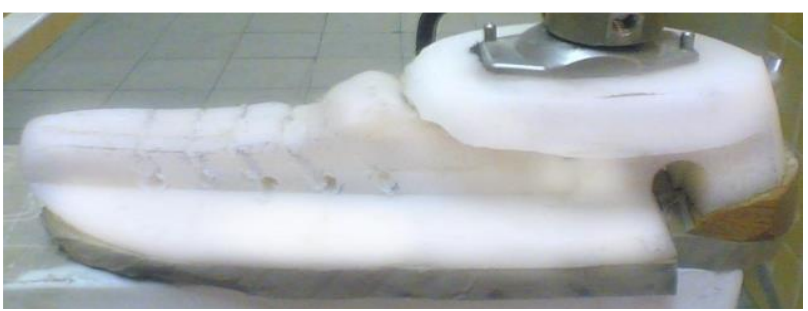

Figure 4. Muslim's foot

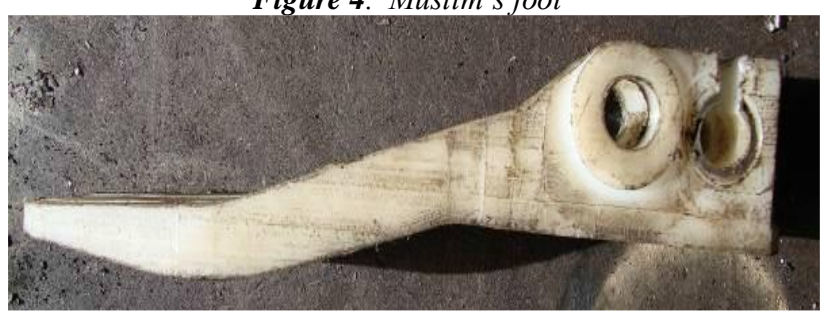

Figure 5. Dr. Emad's foot

The aim of this work was to design and manufacture a new foot made from fiber glass which is lighter and cheaper and easy to manufacture and give a good dorsiflexion angle. From all the above One can suggest a primary shape for new prosthetic foot with dorsiflexion angle and in the range of human walking (5-6) $\mathrm{km} / \mathrm{hr}$. In this research the primary idea is drawn and developed to get fist estimation of dorsiflexion angle in the range above.

The design of the new foot is shown in figure (6).

Figure 6. NEW foot drawing in ANSYS.

Subsequent to upgrading the structure and taking in the thought the capacity for assembling the NEW foot, plan was drawn and dissected with the limited component bundle (ANSYS 13). The NEW foot was checked with the ANSYS and the improvement in the shape was proceeded until the reasonable shape was reached. The foot was made and first model was created, at that point straightforward machining measures were utilized to get last state of items. The NEW foot was analyzed to discover such attributes as dorsiflexion, weight and cost. There are various prosthetic foot plans accessible. These prosthetics feet serve essential capacities which include: uphold the body against gravity during standing and strolling; ingest stun during impact point contact and sometimes imitate metatarsal esophageal capacity during the position period of stride, forestalling the weariness disappointment, putting away vitality as the position appendage acknowledges body weight and returns this vitality as the foot lift off the ground and great lifts off the ground and great dorsiflexion. The state of NEW foot is reliant on dorsiflexion point; the stun assimilation. The new

Mohammed, S. and Mohammed, A., 2021. Design and Manufacturing of a New Prosthetic Foot. Journal port Science Research, 4(2), PP 118-124 
plan takes in thought the requirement for a lighter foot for the older amputee populace and its relative minimal effort. The shape at point $\mathrm{C}$ of the foot lower leg complex makes a joint with a hub of revolution that changes area during the position stage as the body's focal point of the mass continues forward over the foot. At the impact point strikes the hole open and the hole between the two pieces shut permitting plantarflexion to happen as the subject accomplishes foot level and starts to move over the foot. Toward the finish of midstance all holes become shut and contact the head of the forefoot area.

\section{MODELING OF PROSTHETIC FOOT USING ANSYS SOFTWARE}

\subsection{Steps Before Modeling The Specimen .}

To create the finite element model in the ANSYS software, there are three steps before modeling the specimen .

- Choosing element type for each material used:In the first step, the elements type for each material used in the analysis is chosen off. In this study, one element was used, this elements is solid brick 8 node 185 to represent random Eglass-polyester with help from the ANSYS software.

- Defining real constants for these chosen elements: No real constant is used for solid 185 elements.

- Defining material properties for the chosen elements: Material model behavior number 1 refers to solid brick 8node 185element. This element is used to model random E-glasspolyester. The element requires information regarding linear orthotropic as shown in Table below:

Table 1. Element information.

Material properties for solid 185 element / linear orthotropic

Modulus of elasticity in the $\mathrm{x}$-direction $\mathrm{MPa}$

EX

1930

Poison ratios

PRXY 0.231

\subsection{ANSYS Finite Element Model}

The ANSYS is a bundle program that utilizes limited component strategy to ascertain the mathematical arrangement of complex issue whose investigative arrangement is dull or difficult to accomplish. There are numerous means to tackle the issue by ANSYS these are :

1) .Preprocessor, ANSYS program can manage numerous sorts of issues (mechanical, dynamics, thermal, fluid)thus, the initial phase in mechanical branch has been chosen to tackle the issue

2) .Processor. In this progression the reasonable sort of component is picked to tackle the issue. SOLID185 is utilized for the 3-D displaying of strong structures as in the introduced issue. It is characterized by eight hubs having three degrees of opportunity at every hub: interpretations in the nodal $\mathrm{x}, \mathrm{y}$, and $\mathrm{z}$ headings. The component has pliancy, hyper versatility, stress hardening, creep, enormous avoidance, and huge strain abilities. It likewise has blended detailing capacity for mimicking distortions of almost incompressible Elastoplastic materials and completely incompressible hyper versatile materials. The component is characterized by eight hubs and the orthotropic material properties. The default component arrange framework is along worldwide bearings

3) .Create mesh in volumes. The meshing process has been done by choosing the volume and the number of elements in each body. The number of elements was (10290) elements with total number of nodes (20580)

4) .Define load. Loads applied by using either PREP7 preprocessor or the solution processor. Despite the picked system, it is important to characterize the examination type and investigation alternatives, apply loads, specify load step options, and initiate the finite-element solution. The analysis type to be used is based on the loading conditions [Figures 7 , 8 and 9].

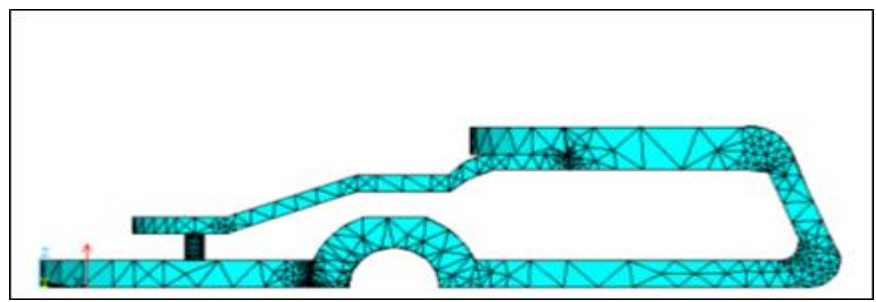

Figure 7. NEW foot keel with load (Toe off phase).

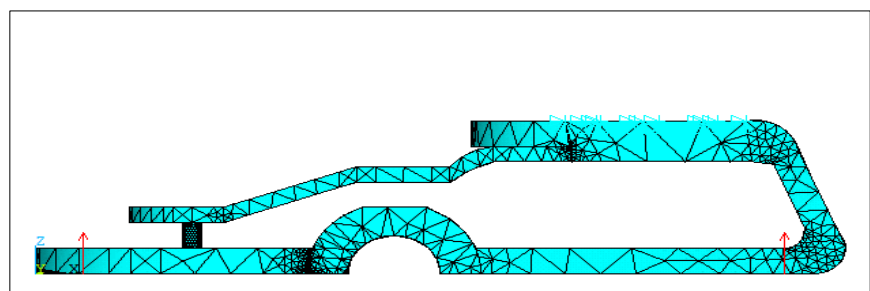

Figure 8. NEW foot keel with load (Midstance phase).

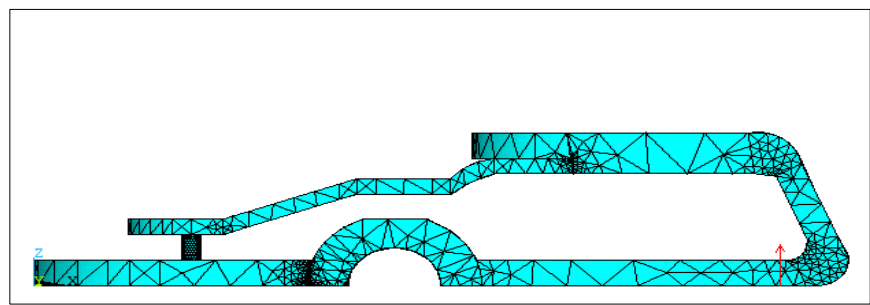

Figure 9. NEW foot keel with load (Heel phase).

5) .Solution. The displacement fixing at explicit purposes of the body is essential to tackle the issue. The body as one piece must be fixed in $(\mathrm{X}, \mathrm{Y}, \mathrm{Z})$ in three dimensional axes. After the displacement is fixed, the load (force or pressure) of each one are applied during the load step that is needed to be solved.

Mohammed, S. and Mohammed, A., 2021. Design and Manufacturing of a New Prosthetic Foot. Journal port Science Research, 4(2), PP 118-124 
6 .General postprocessor. The results can be spoken to as form plot with pressure an incentive at any hub or as ways among stresses and the separation along any way in the body at any stage of the solution.

\section{EXPERIMENTAL WORK}

Numerous tests are suggested for planning and assembling the fake appendage. The introduced foot is new, and afterward it is imperative to analyze the structure, so that, a full size model is made. Then it is tested using the dorsiflexion test. The test results compared with the theoretical procedure to show the difference between the experimental resuts and th theoretical results. The experimental work, in this section includes the following steps :

- $\quad$ Tensile test and three point bending test for the used material.

- Designing and manufacturing a new foot: The NEW foot is made from composite material of fiber glass-polyester, this material has a good flexibility with respect to the applied load in terms of the gap above keel and ankle; The manufacturing stages are as the follows :

1) Drawing of the shape in ANSYS program.

2) Designing and manufacturing two wood molds for the two pecieses of the foot .

3) Machining the molds and framing them by Galvanized iron sheet.

4) Covering the molds with a layer of nylon to prevent the adhesion of the material to the mold

5) Cutting a several sheet of random fiber glass into size fit the mold.

6) Preparing the polyester by adding $5 \mathrm{ml}$ of hardener into each $250 \mathrm{ml}$ of polyester resin .

7) putting fiber layer in the resin layer into the molds and with using brushes and rollers the fiber layer would saturated by resin, then another fiber sheet would be put and repeat the process until the end layer, then rolling over all layers to ensure complete air removal. Finally covering the molds with a layer of nylon and keep them dry for a day.

8) A Jigsaw used to cut the excess material .

9) Holes were made using fixed drill machine with finishing to ensuring smooth surfaces and avoiding stress concentration.

10) Adding natural rubber to the heel to absorb impact. The final shape of product is shown in Figure (10).

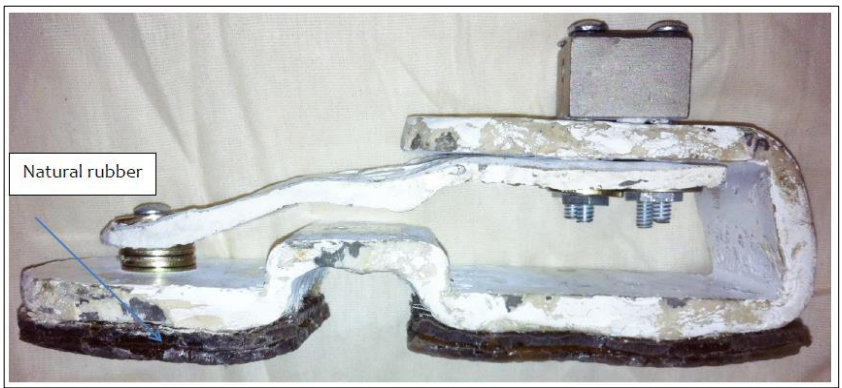

Figure 10. The final new foot .

- Dorsiflexion test: To finish the dorsiflexion test the threesided wood must be fabricated and upheld with an evaluated ruler. This bit of wood is placed in a testometric machine. It is supplanted under cross head. The foot contacts the triangle wood and applies power; this power mimics the ground response power. Dorsiflexion test is applied to the new foot, and an examination was made with an ordinary human foot and SACH foot. The measure of dorsiflexion as identified with the vertical dislodging is in this way controlled by the toe switch of the foot, where the toe switch is the good ways from the joined arch to rotate comparing to the chunk of the foot.

\section{EXPERIMENTAL RESULTS}

The mechanical properties of the used material are shown in figure (11 and 12) and Table below :

Table 2. Mechanical properties of the used material.

\begin{tabular}{ll}
\hline Material & Modulus of elasticity (MPa) \\
\hline Random E-glass-polyester & 1930 \\
\hline
\end{tabular}

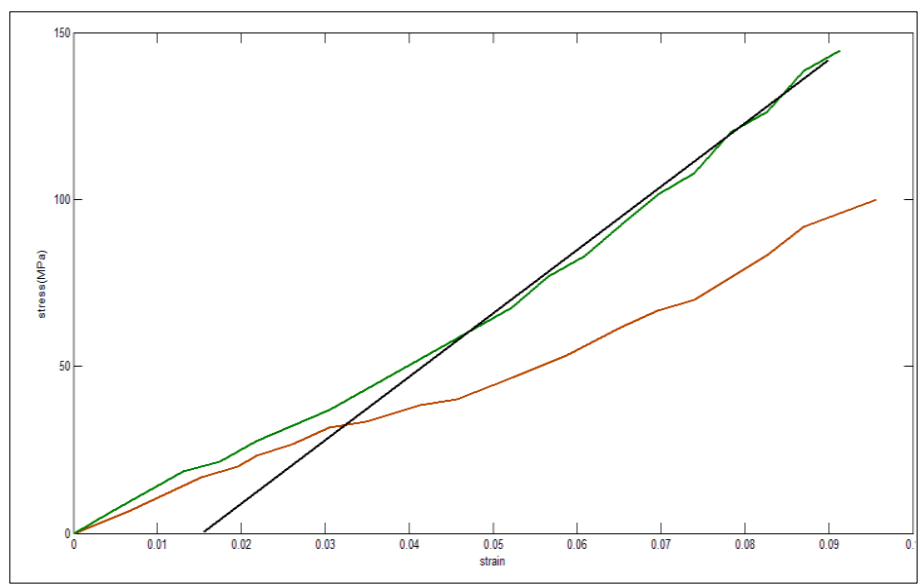

Figure 11. Stress-strain diagram. 


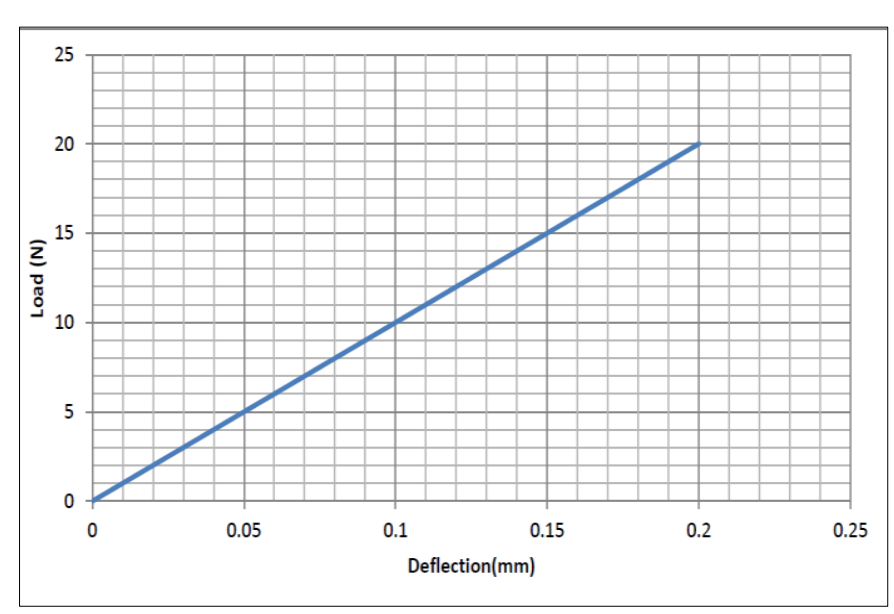

Figure 12. experimental result of bending test.

\subsection{Experimental Results Obtained from Foot (Dorsiflexion test) :}

Figure (13) show the result of the displacement of the foot at different load that we can determine the dorsiflexion angle for NEW foot from it. The dorsiflexion angles were obtained using a digital camera. The maximum dorsiflexion angles for normal human foot, SACH foot, and NEW foot are tabulated in Table below:

Table 3. Dorsiflexion angle for different types of feet (load $=950$ $N)$.

\begin{tabular}{ll} 
Type of foot & Dorsi-flexion angle \\
\hline Normal human foot & $4.2^{\circ}$ \\
SACH foot & $6.4^{\circ}$ \\
NEW foot & $7^{\circ}$ \\
\hline
\end{tabular}

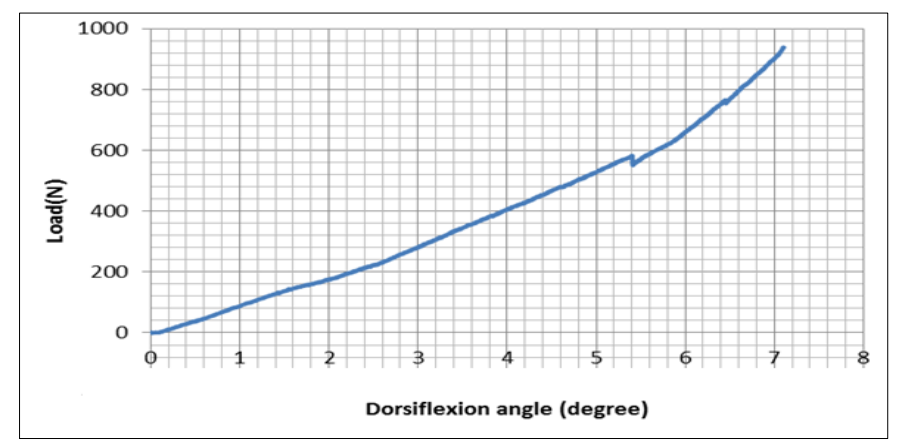

Figure 13. Experimental load with dorsiflexion for NEW design foot.

\subsection{Numerical Analysis Results and discussion.}

Static Analysis. This analysis aims to investigate the stresses and deformations of clamped NEW foot with force after assuming that this value is the average of applied load $(950 N)$. Figures (14) and (15) show the Von-Mises stresses distribution of deformation in the NEW foot is in the toe off phase with force of $(950 \mathrm{~N})$. Figure (14) shows the distribution of Von-Mises stresses in the NEW foot is shown on this figure and its location is located in the heel hole with Von-Mises stress value of 53.1 MPa. Figure (15) shows the distribution of deformation on the top or bottom surface of the NEW foot. It can be seen from the figure that the maximum deflection is located in the toe off foot and we can determine the dorsiflexion angle from it which found to be $6.77^{\circ}$. Figures (16) and (17) show the Von-Mises stresses and distribution of deformation in the NEW foot is the heel strikes phase with force of $(950 \mathrm{~N})$. Figure (16) shows the distribution of Von-Mises stresses in the NEW foot is shown on this figure and its location is located in the heel hole with Von-Mises stress value of 12.29 Mpa Figure (17) shows the distribution of deformation on the top or bottom surface of the NEW foot. It can be seen from the figure that the maximum deflection is located in the toe off foot. Figures (18) and (19) show Von-Mises stresses and the distribution of deformation in the NEW foot is the midstance phase with force of $(730 \mathrm{~N})$. Figure (18) shows the distribution of VonMises stresses in the NEW foot is pointed on this figure and its location is located in the heel hole with Von-Mises stress value of $41.77 \mathrm{MPa}$. Figure (19) shows the distribution of deformation on the top or bottom surface of the NEW foot. It can be seen from the figure that the maximum deflection is located in the toe off and heel foot. The figures shows that the stress and deflection for the Toe off phase is the greater due to increasing the bending moment because this phase has a longer bending arm. The dorsiflexion angle that we found it by analytical method less than that of experimental method because in the first method we assume a Homogeneous distribution of the material of the foot while in practical it is not exactly homogeneous.

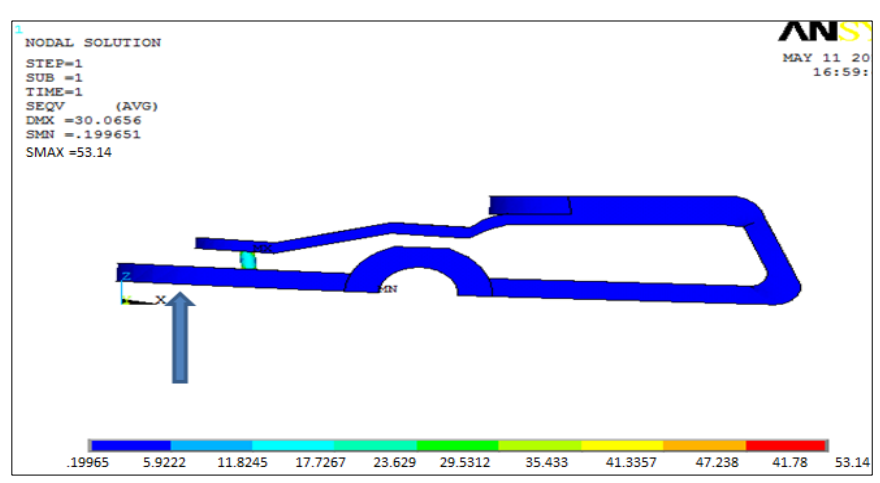

Figure 14. Von_Mises stress contour of the NEW foot (toe off phase).

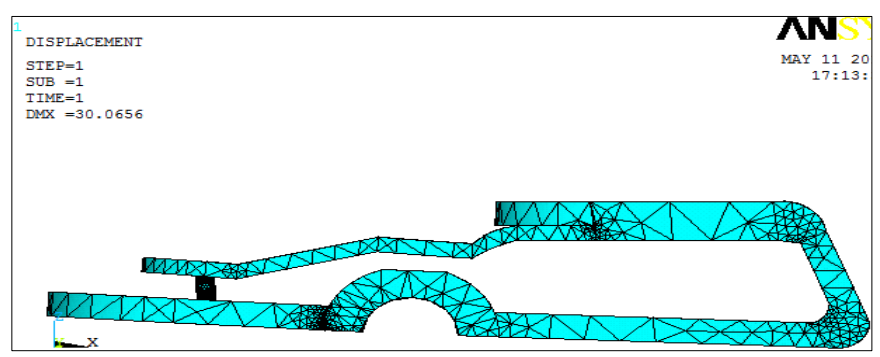

Figure 15. Deformation of the NEW foot (toe off phase). 


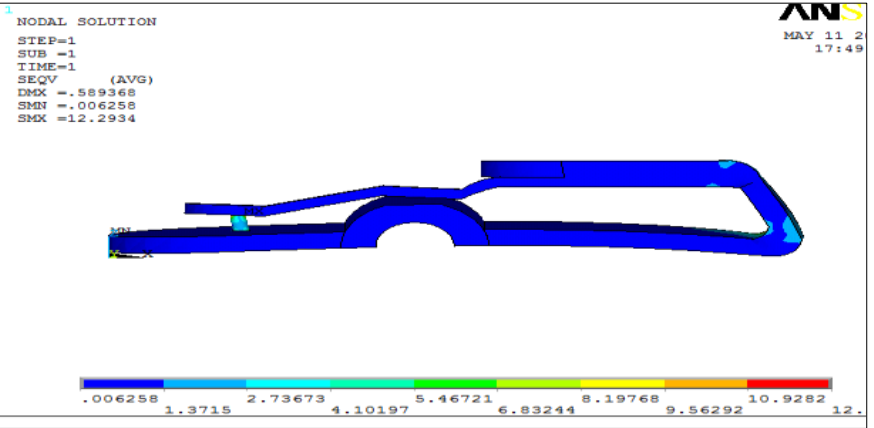

Figure 16. Von-Mises stress contour of the NEW foot (heel strikes phase).

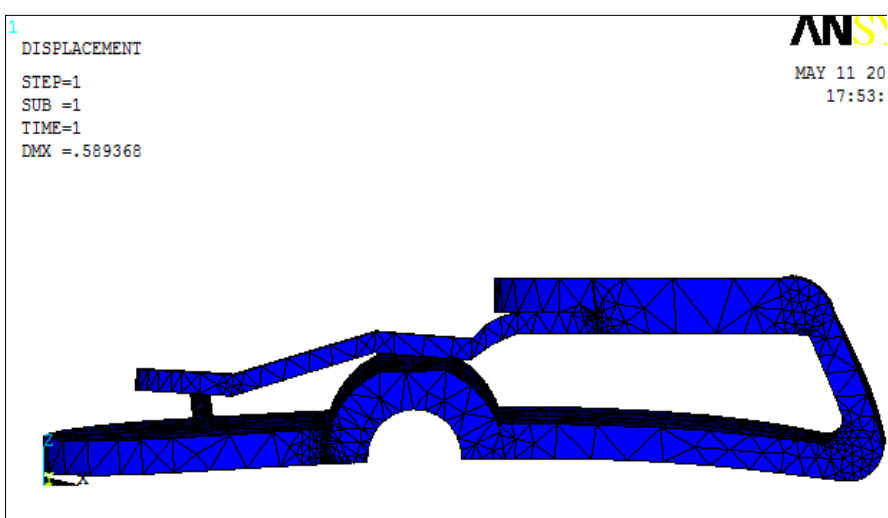

Figure 17. Deformation of the NEW foot(heel strikes phase).

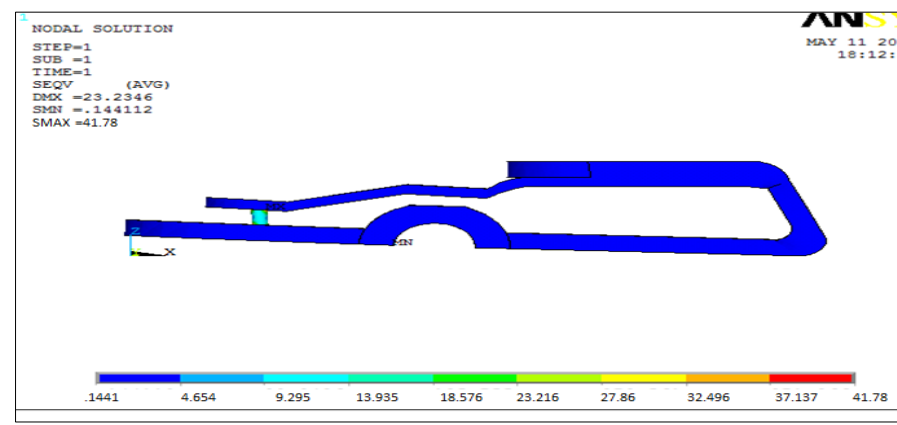

Figure 18. Von-Mises stress contour of the new foot (midstance phase)

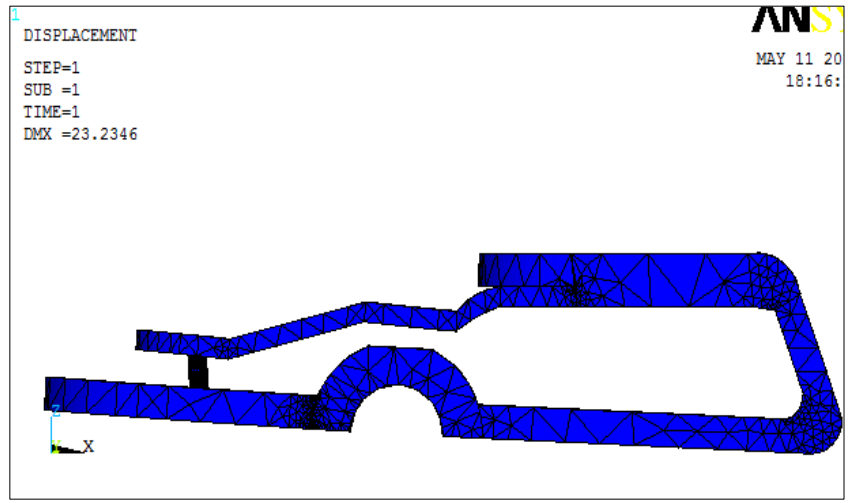

Figure 19. Deformation of the NEW foot (midstance phase).

\section{CONCLUSIONS}

From the outcomes got both the theoretically and experimentally accompanying end can be drawn

1) Using of E-glass polyester composite in manufacturing the designed NEW foot gives high dorsiflexion angle which is a good result .

2) The dorsiflexion angle for the NEW foot is more than that of the SACH foot, so may surrender a curve to a satisfactory cutoff.

3) The unique structure with opened locale on the lower of the NEW foot makes an addition in dorsiflexion point so it prompts greater adaptability in step profile

4) The NEW foot is compared with SACH foot in cost and weight, the NEW foot is lighter in weight and cheaper.

\section{REFERENCES}

[1] Nassan, S. (2000). The latest designs in prosthetic feet. Physical Medicine and Rehabilitation Clinics of North America. W.B. Saunders. https://doi.org/10.1016/s1047-9651(18)30122-0

[2] Hamad, Q. A., Oleiwi, J. K., \& Abdulrahman, S. A. (2021). Tensile properties of laminated composite prosthetic socket reinforced by different fibers. Materials Today: Proceedings. https://doi.org/10.1016/j.matpr.2021.06.348

[3] Agrawal, V., Gailey, R. S., Gaunaurd, I. A., O’Toole, C., \& Finnieston, A. A. (2013). Comparison between microprocessor-controlled ankle/foot and conventional prosthetic feet during stair negotiation in people with unilateral transtibial amputation. Journal of Rehabilitation Research and Development, 50(7), 941-950. https://doi.org/10.1682/JRRD.2012.05.0093

[4] El-Mohandes, M. S., \& El-Hussien Ibrahem, M. (2015). Stiffness analyses of modified niagara prosthetic feet using finite element modelling. In Proceedings of the 7th Cairo International Biomedical Engineering Conference, CIBEC 2014 (pp. 19-23). Institute of Electrical and Electronics Engineers Inc. https://doi.org/10.1109/CIBEC.2014.7020953 
[5] Khan, S. F., Noor, Z. N. M., \& Rani, A. M. A. (2021). Analysis and evaluation of optimized lower limb prosthetic device. In Journal of Physics: Conference Series (Vol. 2051). IOP Publishing Ltd. https://doi.org/10.1088/1742$\underline{6596 / 2051 / 1 / 012040}$

[6] Resan, K. K., Hilli, A., \& Ali, M. (2011). DESIGN AND ANALYSIS OF A NEW PROSTHETIC FOOT FOR PEOPLE OF SPECIAL NEEDS تصديم. The Iraqi Journal For .Mechanical And Material Engineering (Vol. 11)

[7] Oleiwi, J. K., \& Hadi, A. N. (2021). Properties of Materials and Models of Prosthetic Feet: A Review. IOP Conference Series: Materials Science and Engineering, 1094(1), 012151. https://doi.org/10.1088/1757$\underline{899 x / 1094 / 1 / 012151}$ 